\title{
The Behavior and Role of Lipolysis-stimulated Lipoprotein Receptor, a Component of Tricellular Tight Junctions, in Head and Neck Squamous Cell Carcinomas
}

\author{
KENICHI TAKANO ${ }^{1}$, TAKUYA KAKUKI ${ }^{1,2}$, KAZUFUMI OBATA $^{1}$, KAZUAKI NOMURA $^{1}$, \\ RYO MIYATA ${ }^{1}$, ATSUSHI KONDO ${ }^{1}$, MAKOTO KUROSE ${ }^{1}$, AKITO KAKIUCHI ${ }^{1,2}$, \\ YAKUTO KANEKO $^{1,2}$, TAKAYUKI KOHNO ${ }^{2}$, TETSUO HIMI ${ }^{1}$ and TAKASHI KOJIMA ${ }^{2}$ \\ Departments of ${ }^{1}$ Otolaryngology and ${ }^{2}$ Cell Science, Research Institute for Frontier Medicine, \\ Sapporo Medical University School of Medicine, Sapporo, Japan
}

\begin{abstract}
Background/Aim: Lipolysis-stimulated lipoprotein receptor (LSR) knockdown has also been reported to increase the motility and invasiveness of certain cancer cells. Here, we describe, for the first time, the behavior and role of LSR in head and neck squamous cell carcinoma (HNSCC) in vivo and in vitro. Materials and Methods: Samples of HNSCC, normal palatine tonsils, the pharynx carcinoma cell line Detroit562 and primary cultured HNSCC were characterized by immunostaining, western blot, real-time polymerase chain reaction (PCR), Matrigel invasion and proliferation assays. Results: Protein and mRNA of LSR were strongly expressed, as well as claudin-1 in HNSCC tissues than in normal tissues, especially in invasive tissues. Knock-down of LSR and claudin-1 (CLDN-1), but not tricellulin (TRIC) by siRNAs, markedly induced invasiveness of Detroit562 cells and primary cultured HNSCC. LSR inhibited the development and progression of HNSCC. Conclusion: LSR is a potential target for new forms of head and neck cancer therapy.
\end{abstract}

Head and neck cancers, including those in the pharynx, larynx, tongue, oral cavity, nasal cavity and paranasal cavity, account for a large number of deaths and morbidity worldwide with over 500,000 new cases reported annually (1). Most head and neck cancers are squamous cell carcinomas and risk factors include tobacco exposure and alcohol dependence for cancers in the oral cavity, larynx, oropharynx and hypopharynx, as well as infection with

Correspondence to: Kenichi Takano, Department of Otolaryngology, Sapporo Medical University School of Medicine, South-1, West-16, Chuo-ku, Sapporo 060-8543, Japan. Tel: +81 116889655, Fax: +81 116155405, e-mail: kent@sapmed.ac.jp

Key Words: Lipolysis-stimulated lipoprotein receptor, tricellulin, claudin, tight junctions, head and neck cancer. oncogenic viruses for cancers in the nasopharynx and oropharynx. Although current standard treatments combining surgery, radiotherapy and chemotherapy are aggressive and multimodal, long-term survival rates are poor (1). Therefore, novel therapeutic targets and prognostic factors are desired.

The tight junction between epithelial cells maintains cell polarity and regulates the flow of solutes through paracellular spaces (2). Where bicellular tight junctions converge, as happens when three epithelial cells meet in polarized epithelia, tricellular tight junctions, a strong barrier for the cellular sheet, are formed (3). Formation of tricellular contacts also requires lipolysis-stimulated lipoprotein receptor (LSR), a newly identified component (4). In particular, LSR recruits tricellulin, the first molecule incorporated into tricellular tight junctions (3), via interactions between the cytoplasmic domains of both proteins (4).

Loss of tight junctions compromises cell polarity, promotes dedifferentiation and enhances tumor progression (5). In tricellular tight junctions, tricellulin is down-regulated in fibrolamellar carcinoma of the liver and in squamous cell carcinoma of the tonsil $(6,7)$. In addition, tricellulin expression in pancreatic cancer is significantly and negatively correlated with the degree of differentiation such that well-differentiated pancreatic ductal adenocarcinomas significantly overexpress tricellulin, while poorly differentiated adenocarcinomas do not (8). Furthermore, tricellulin expression in gastric carcinoma cells is inhibited by Snail-induced epithelial-mesenchymal transition (9).

In contrast, overexpression of tight junction proteins, such as some claudins and junction adhesion molecule-A, was recently reported to be associated with tumor growth and metastasis $(6,10)$. Indeed, high tricellulin expression is correlated with poor prognosis in hepatocellular carcinoma, although low expression is associated with better outcomes in intrahepatic cholangiocarcinoma (11). Increased tricellulin expression is also associated with better survival in human 
hepatoblastoma (12). Similarly, LSR is believed to be associated with tumor progression (13). LSR knockdown increases the motility and invasiveness of bladder and endometrial cancer cells $(14,15)$. However, the specific pathological role of LSR in head and neck cancer, if any, remains undefined. Thus, we investigated the behavior and role of LSR in head and neck cancer cells in vivo and in vitro.

\section{Materials and Methods}

Human tissues. Palatine tonsils, used as normal control, were obtained from three patients with tonsil hypertrophy who underwent tonsillectomy at Sapporo Medical University, Sapporo, Japan. Head and neck cancer tissues were obtained by tumor resection from another four patients at Sapporo Medical University. Informed consent was obtained from all patients and the study was approved by the ethics committee of Sapporo Medical University.

Reagents and antibodies. Rabbit polyclonal antibodies against LSR, tricellulin and claudin-1 were obtained from Zymed Laboratories (San Francisco, CA, USA). Anti-rabbit and anti-mouse IgG conjugated to Alexa 488 (green) and Alexa 594 (red), respectively, were purchased from Molecular Probes, Inc. (Eugene, OR, USA).

Culture of cancer cell line. The pharynx carcinoma cell line Detroit562 (CCL138) was purchased from American Type Culture Collection (Manassas, VA, USA) and cultured in minimum essential medium (Sigma-Aldrich, St. Louis, MO, USA) supplemented with $10 \%$ fetal bovine serum (Invitrogen, Carlsbad, CA, USA), $100 \mathrm{U} / \mathrm{ml}$ penicillin, $100 \mu \mathrm{g} / \mathrm{ml}$ streptomycin and $50 \mu \mathrm{g} / \mathrm{ml}$ amphotericin B. Cells were then plated on 60-mm culture dishes (Corning Glass Works, Corning, NY, USA) coated with rat tail collagen $(500 \mu \mathrm{g}$ dried tendon $/ \mathrm{ml} 0.1 \%$ acetic acid) and grown at $37^{\circ} \mathrm{C}$ in a humidified incubator with $5 \% \mathrm{CO}_{2}$ and 95\% air. Cells were then treated for $24 \mathrm{~h}$ with inhibitors of signal transduction pathways, each at $10 \mu \mathrm{M}$. Furthermore, cells were incubated for $48 \mathrm{~h}$ in hypoxic conditions of $2 \% \mathrm{O}_{2}$.

Isolation and culture of human head and neck cancer cells. Human head and neck cancer tissues were minced into pieces of 2-3 $\mathrm{mm}^{3}$ in volume and washed with phosphate-buffered saline (PBS) containing antibiotics four times. These tissue specimens were suspended in $10 \mathrm{ml}$ of dispersing solution with $0.5 \mu \mathrm{g} / \mathrm{ml}$ DNase I (Sigma) and $0.08 \mathrm{mg} / \mathrm{ml}$ Liberase Blenzyme (Roche, Basel, Switzerland) in PBS and then incubated at $37^{\circ} \mathrm{C}$ for $20 \mathrm{~min}$. The dissociated specimens were subsequently filtered with $300 \mu \mathrm{m}$ mesh followed by filtration with $40 \mu \mathrm{m}$ mesh. After centrifugation at $1,200 \times g$ for $3 \mathrm{~min}$, the cells were cultured in serum-free bronchial epithelial growth medium ((BEBM); Clonetics Corp. San Diego, CA, USA) supplemented with $0.5 \mu \mathrm{g} / \mathrm{ml}$ hydrocortisone, $5 \mu \mathrm{g} / \mathrm{ml}$ insulin, $10 \mu \mathrm{g} / \mathrm{ml}$ transferrin, $0.5 \mu \mathrm{g} / \mathrm{ml}$ epinephrine, $6.5 \mu \mathrm{g} / \mathrm{ml}$ triiodothyronine, $50 \mu \mathrm{g} / \mathrm{ml}$ gentamycin, $50 \mu \mathrm{g} / \mathrm{ml}$ amphotericin B $0.1 \mathrm{ng} / \mathrm{ml}$ retinoic acid, $0.5 \mathrm{ng} / \mathrm{ml}$ epidermal growth factor (Lonza Walkersville, Inc., Walkersville, MD, USA), bovine pituitary extract ( $1 \%$ vol/vol; Pel-Freez Biologicals, Rogers, AR, USA), $100 \mathrm{U} / \mathrm{ml}$ penicillin and $100 \mu \mathrm{g} / \mathrm{ml}$ streptomycin (Sigma-Aldrich). The primary cultured cells were plated on $60-\mathrm{mm}$ culture dishes (Corning Glass Works, Corning, NY, USA) coated with rat tail collagen (500 $\mu \mathrm{g}$ dried tendon $/ \mathrm{ml} 0.1 \%$ acetic acid) in a humidified, $5 \% \mathrm{CO}_{2}: 95 \%$ air incubator at $37^{\circ} \mathrm{C}$.
RNA interference and transfection. Duplex siRNAs against LSR (HSS147503), tricellulin (HSS1358) and claudin-1 (HSS113420) were synthesized by Thermo Fisher Scientific (Waltham, MA, USA) and transfected using Lipofectamine ${ }^{\mathrm{TM}}$ RNAiMAX Reagent (Invitrogen) into Detroit562 cells that had been pre-seeded on plates for $24 \mathrm{~h}$.

Immunohistochemistry. Clinical tissue samples were fixed in $10 \%$ formalin prepared in phosphate-buffered saline, embedded in paraffin and sectioned at $5 \mu \mathrm{m}$. Sections were then dewaxed in xylene, rehydrated in ethanol and heated with Vision BioSystems Bond Max using ER2 solution (Leica, Takadanobaba, Tokyo, Japan) in an autoclave to retrieve antigens. Endogenous peroxidase was blocked for 10 min with $3 \%$ hydrogen peroxide in methanol. Sections were then washed twice with Tris-buffered saline, blocked with Block Ace for $1 \mathrm{~h}$, washed another time with Tris-buffered saline and probed for $1 \mathrm{~h}$ with antibodies against LSR (1:100), tricellulin (1:100), MIB1 (1:20) and claudin-1 (1:100). Samples were then washed three times in Tris-buffered saline, processed with Vision BioSystems Bond Polymer Refine Detection Kit DS9800, washed another three times in Tris-buffered saline and stained with a working solution of diamino-benzidine tetrahydrochloride. Finally, sections were counterstained with hematoxylin.

$R N A$ isolation and real-time polymerase chain reaction $(P C R)$. Total RNA was extracted, purified using TRIzol (Invitrogen) and reversetranscribed into cDNA in $20-\mu l$ reactions containing $1 \mu \mathrm{g}$ total RNA, oligodT and Superscript II reverse transcriptase, following the manufacturer's recommendations (Invitrogen). Reactions were incubated for $50 \mathrm{~min}$ at $42^{\circ} \mathrm{C}$ and terminated by incubation for $15 \mathrm{~min}$ at $70^{\circ} \mathrm{C}$. Targets were then amplified by PCR according to the manufacturer's recommendations (Takara, Kyoto, Japan) in 20$\mu \mathrm{l}$ reactions containing $100 \mathrm{pM}$ primer pairs, $1.0 \mu \mathrm{l} \mathrm{cDNA}, \mathrm{PCR}$ buffer, dNTPs and Taq DNA polymerase. Reactions consisted of as many as 30 cycles, depending on the PCR primer pair, at $96^{\circ} \mathrm{C}$ for $15 \mathrm{~s}, 55^{\circ} \mathrm{C}$ for $30 \mathrm{~s}$ and $72^{\circ} \mathrm{C}$ for $60 \mathrm{~s}$, followed by final extension at $72^{\circ} \mathrm{C}$ for $7 \mathrm{~min}$. Products $(7 \mu \mathrm{l})$ were analyzed by $2 \%$ agarose gel electrophoresis, stained with ethidium bromide and sized using GeneRuler 100 bp DNA ladder (Fermentas, Ontario, Canada). LSR was amplified with sense primer 5'-CAGGACCTCAGAA GCCCCTGA-3' and antisense primer 5'-AACAGCACTTGTCT GGGCAGC-3', while tricellulin (TRIC) was amplified with sense primer 5'-TCAGACAGATGATGAGCGAGA-3' and antisense primer 5'-ATGTTCCTGTCGGCTTTCC-3'. Sense primer 5'-AAC GCGGGGCTGCAGCTGTTG-3' and antisense primer 5'-GGATA GGGCCTTGGTGTTGGGT-3' were used to amplify claudin-1 $(C L D N-1)$. Real-time PCR was performed with a TaqMan Gene Expression Assay Kit on a StepOnePlus ${ }^{\mathrm{TM}}$ real-time PCR system (Applied Biosystems, Foster City, CA, USA). Ribosomal RNA (18S, Hs99999901) was used to standardize expression of junction adhesion molecule-A (Hs00170991) and $\beta$-catenin (Hs00258305). Relative mRNA levels between control and test samples were calculated by the $\Delta \Delta \mathrm{CT}$ method and are reported as means of triplicate experiments with $95 \%$ confidence intervals (CIs).

Western blot. Cultured cells were scraped from $60 \mathrm{~mm}$ dishes into $300 \mu \mathrm{l}$ buffer containing $1 \mathrm{mM} \mathrm{NaHCO} 3$ and $2 \mathrm{mM}$ phenylmethylsulfonyl fluoride, collected in microcentrifuge tubes and sonicated for $10 \mathrm{~s}$. The protein concentration in the resulting lysate was determined using a BCA Protein Assay Reagent Kit (Pierce Chemical Co., Rockford, IL, USA). Aliquots (15 $\mu \mathrm{l} / \mathrm{lane})$ were separated by 

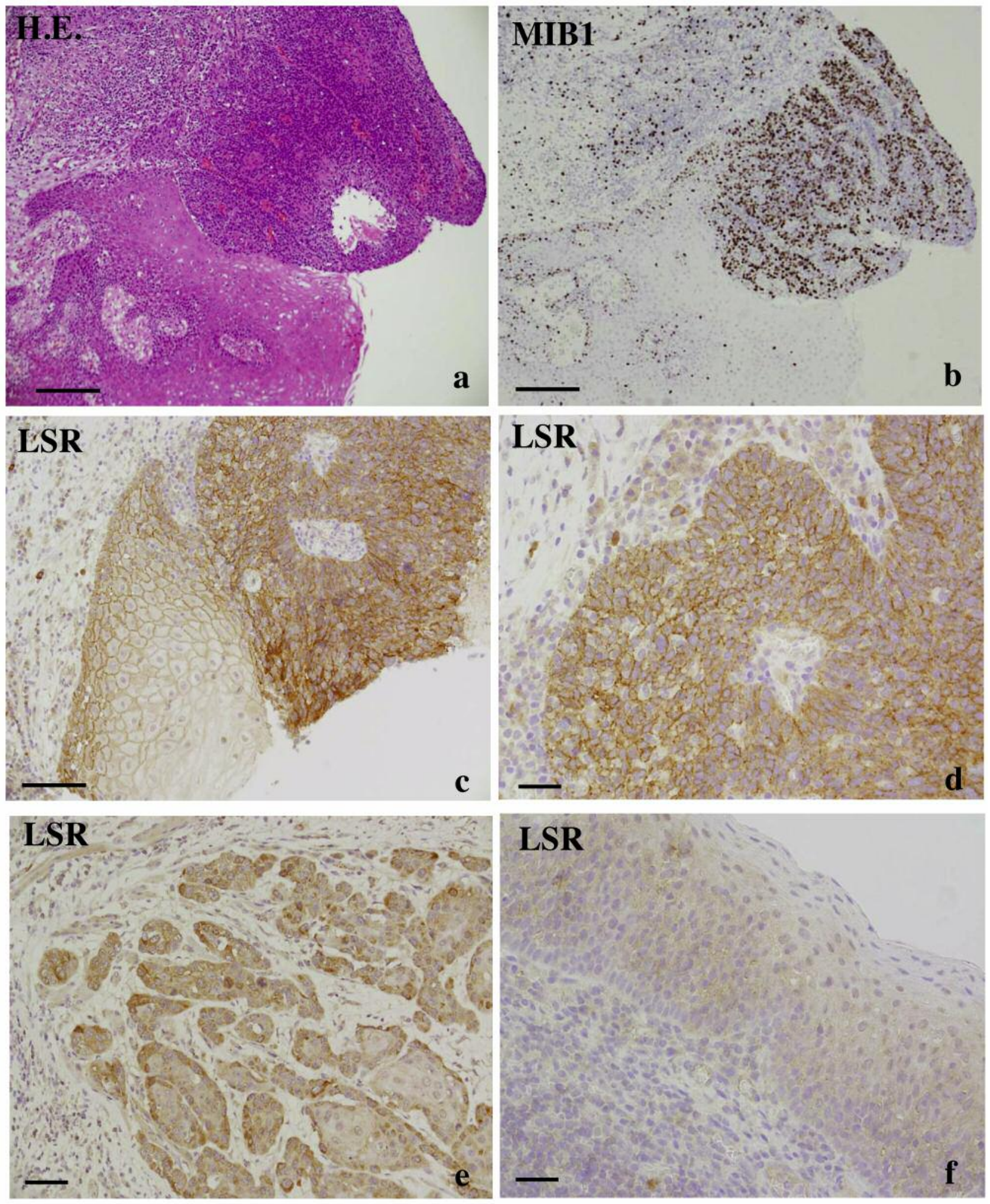

Figure 1. Expression of LSR and MIB1 in head and neck cancer tissues. (A) Hematoxylin and eosin (H.E.) staining of head and neck cancer and dysplasia. (B) Immunohistochemical staining for MIB1 and (C) LSR in head and neck cancer and dysplasia. (D) Immunohistochemical staining for LSR in head and neck cancer and dysplasia, (E) in invasive tissue and (F) in the epithelium of normal tonsil. Scale bar, $100 \mu \mathrm{m}$. 

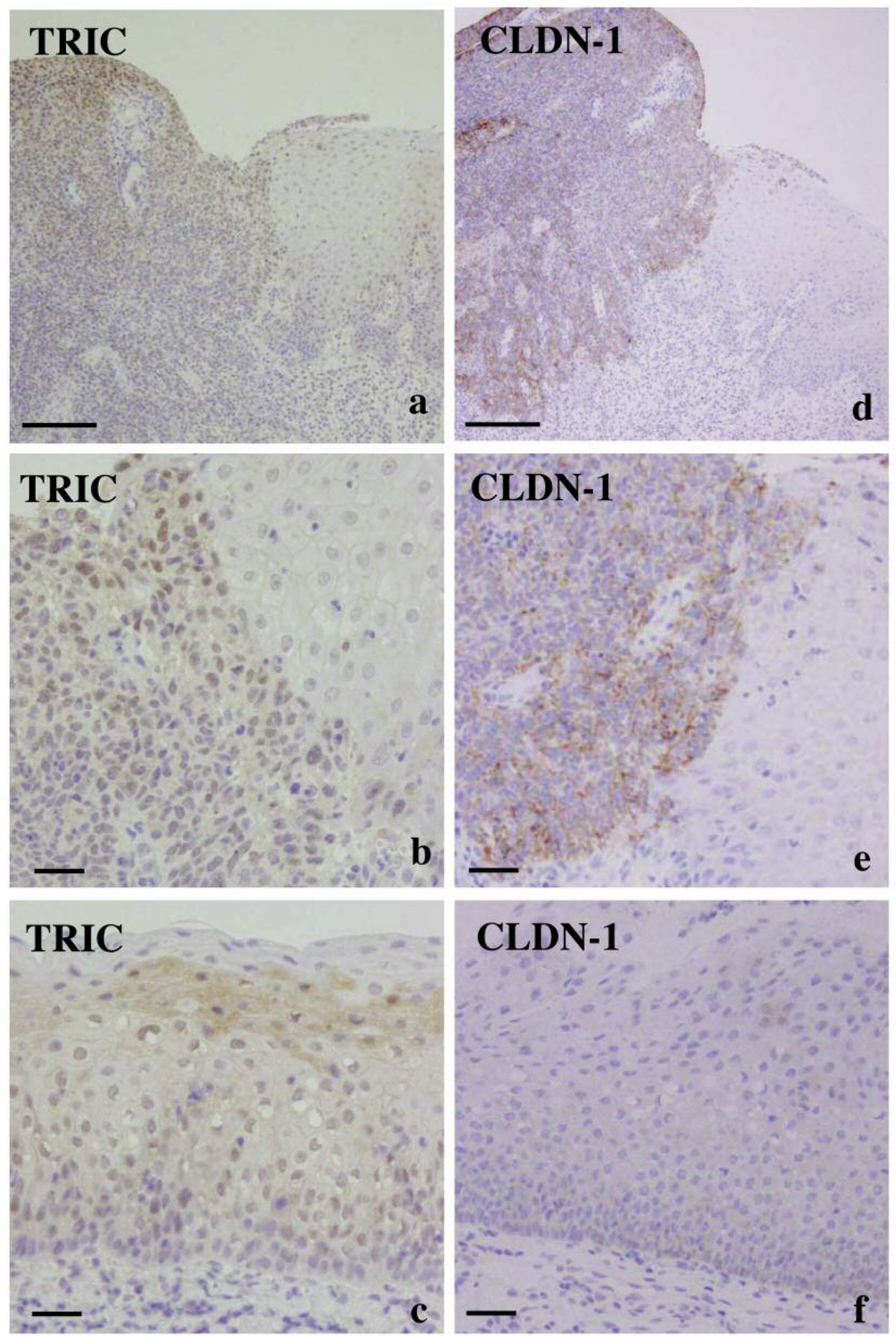

Figure 2. Expression of tricellulin and claudin-1 in head and neck cancer tissues. Immunohistochemical staining for (A) tricellulin (TRIC) and (D) claudin-1(CLDN-1) in head and neck cancer and dysplasia. $(B, E)$ High-power field of $(A, D)$. (C) Immunohistochemical staining for tricellulin and $(F)$ claudin-1 in the epithelium of normal tonsil. Scale bar, $100 \mu \mathrm{m}$. 

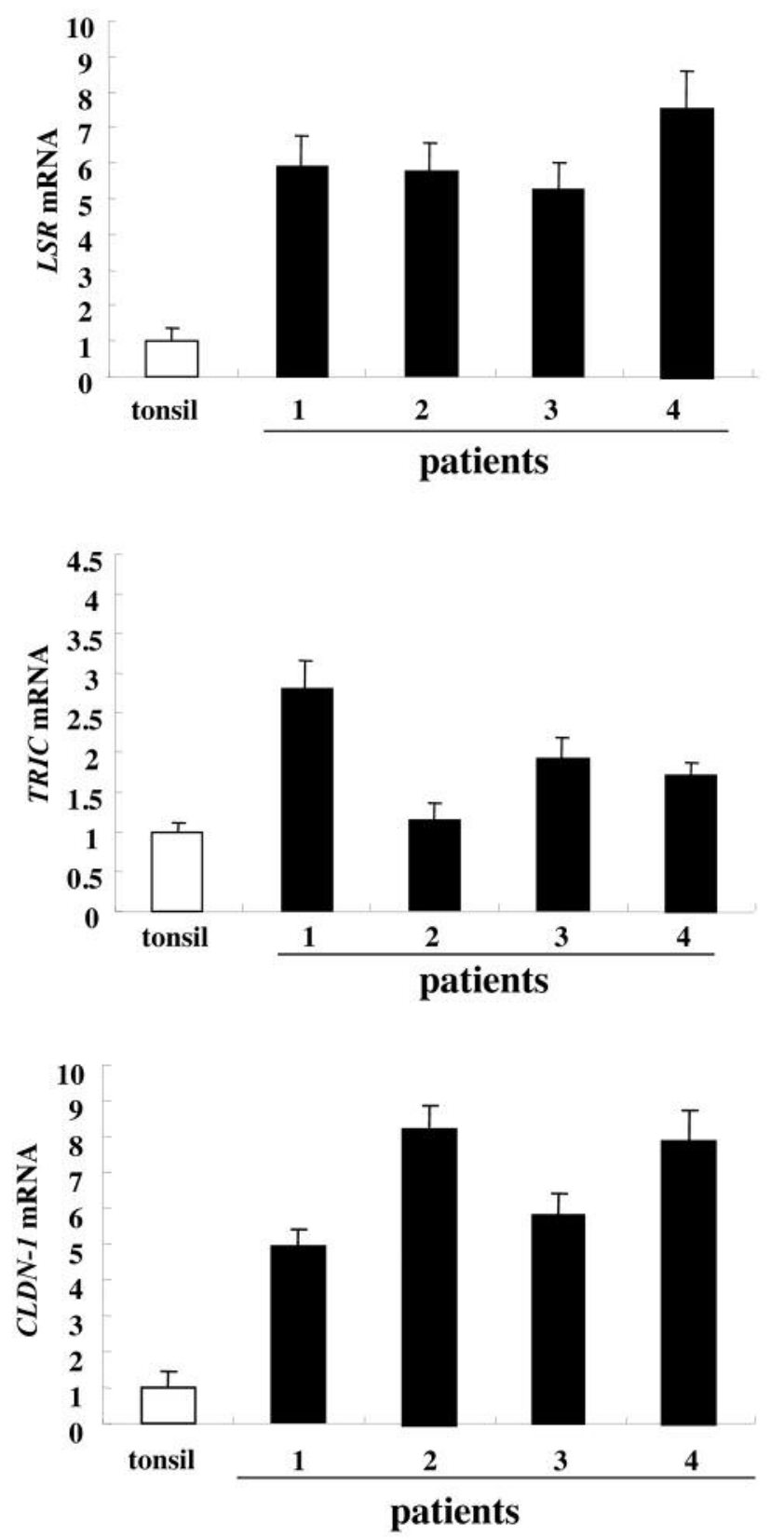

Figure 3. Real-time PCR of LSR, tricellulin (TRIC) and claudin-1 $(C L D N-1)$ in normal tonsil and head and neck cancer tissues.

electrophoresis on 5-20\% SDS-polyacrylamide gels (Wako, Osaka, Japan) and transferred to a nitrocellulose membrane (Immobilon; Millipore Co., Bedford, UK). The membrane was blocked for $30 \mathrm{~min}$ at room temperature with $25 \mathrm{mM}$ Tris $\mathrm{pH} 8.0,125 \mathrm{mM} \mathrm{NaCl}, 0.1 \%$ Tween 20 and $4 \%$ skim milk, probed for $1 \mathrm{~h}$ at room temperature with polyclonal rabbit antibodies against LSR $(1: 1,000)$, tricellulin $(1: 1,000)$, claudin- $1(1: 1,000)$ and actin $(1: 1,000)$ and, finally, labeled for $1 \mathrm{~h}$ at room temperature with anti-mouse and anti-rabbit IgG conjugated to horseradish peroxidase. Immunoreactive bands were detected using an ECL Western blot system.
Matrigel invasion assay. Matrigel (Becton Dickinson Labware, Bedford, MA, USA) and Cell Culture Insert with pore size $8 \mu \mathrm{m}$ (Becton Dickinson Labware, Franklin Lakes, NJ, USA) were used to measure invasiveness. Detroit562 cells were plated onto the upper chamber of a Transwell coated with Matrigel, with the lower chamber being filled with conditioned medium from human fibroblast cultures, and supplemented with $10 \mathrm{nM}$ epidermal growth factor (EGF) as adhesive substrate. The system was then incubated for $24 \mathrm{~h}$, at which point the upper chamber was fixed with $100 \%$ methanol for $10 \mathrm{~min}$, and stained with Giemsa for $20 \mathrm{~min}$. Areas of invading cells were measured by microscopy (Olympus, Tokyo, Japan).

Proliferation assay. Cells were seeded onto 96-well culture plates (Corning, New York, NY, USA) and assayed daily in triplicate with Cell Counting Kit-8 (Wako, Osaka, Japan), following the manufacturer's instructions. Absorbance at $450 \mathrm{~nm}$ was measured on an iMark Microplate Reader (Bio-Rad, Hercules, CA, USA).

Data analysis. Representative results of at least three separate experiments are shown with data reported as mean \pm SEM. Differences between groups were tested by analysis of variance, followed by a post-hoc test and an unpaired two-tailed Student's $t$-test.

\section{Results}

Expression and distribution of LSR, tricellulin and claudin-1 in dysplasia and head and neck squamous cell carcinoma. The expression and distribution of LSR were investigated by immunohistochemistry in clinical samples of head and neck squamous cell carcinoma. LSR was expressed more abundantly in cancer tissue than in adjacent dysplastic tissue (Figure 1A, C). In particular, LSR was predominantly expressed at the membrane of cancer cells, that also strongly expressed MIB1, a marker of proliferation (Figure 1B, D). Furthermore, LSR was highly expressed in invasive tissue (Figure 1E) but was very weakly expressed in normal tonsils (Figure 1D).

The expression and distribution of tricellulin and claudin1 were also investigated. Abundant claudin-1 expression was observed in cancer tissues (Figure 2D), whereas tricellulin expression was lower than that of LSR and claudin-1 (Figure 2A). Claudin-1 was also expressed at the membrane (Figure $2 \mathrm{E}$ ); in contrast, tricellulin was positive in the nuclei of some cancer cells (Figure 2B). In normal tonsils, tricellulin was detected in the epithelium (Figure 2C) but claudin-1 was only weakly expressed (Figure $2 \mathrm{~F}$ ).

Real-time PCR was used to determine changes in mRNA expression of $L S R$, tricellulin (TRIC) and claudin-1 (CLDN-1) (Figure 3). In cancer tissues, $L S R$ mRNA and $C L D N-1$ mRNA were approximately 5- to 8-fold more abundant than in normal tonsils (Figure 3A, C). Similarly, TRIC mRNA was <3-fold higher in cancer tissues than in normal tonsils (Figure $3 \mathrm{~B}$ ).

Knockdown of LSR and claudin-1 promotes invasiveness in Detroit562 cells. LSR, tricellulin and claudin-1 were knocked down by siRNAs in Detroit562 cells to investigate their role in head and neck cancer. In Detroit562, RT-PCR 
$\mathbf{a}$

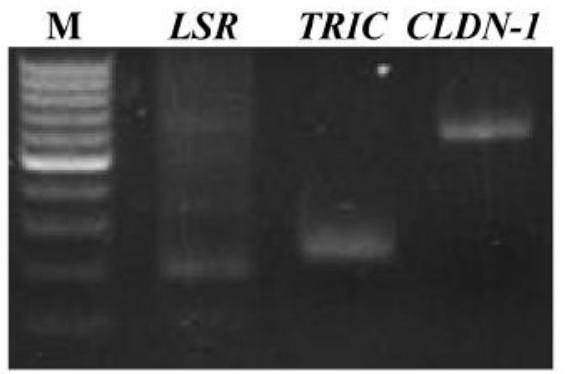

b

TRIC

\section{CLDN-1}

actin

c
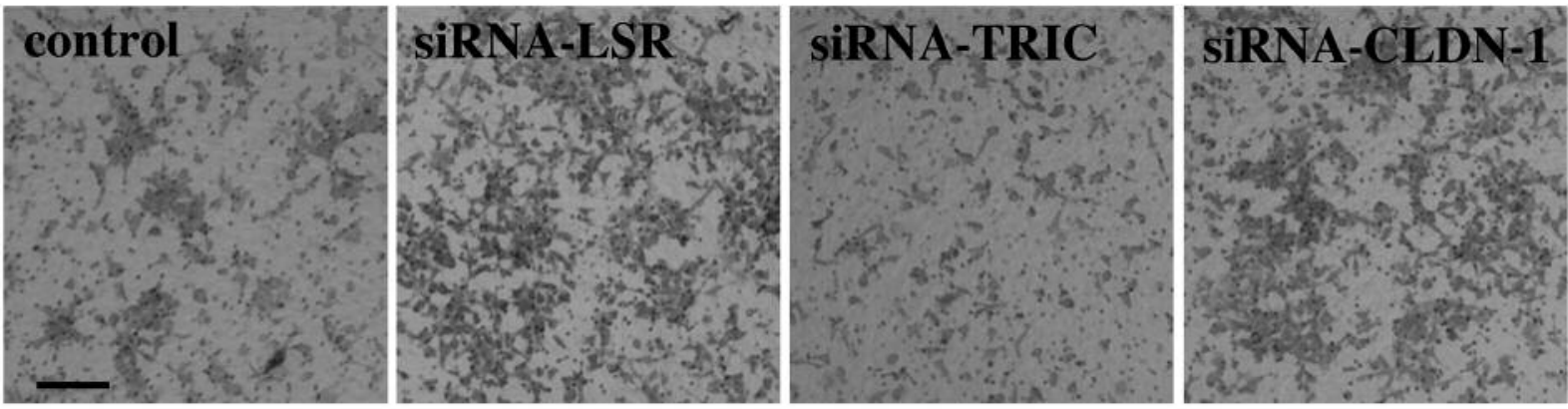

d
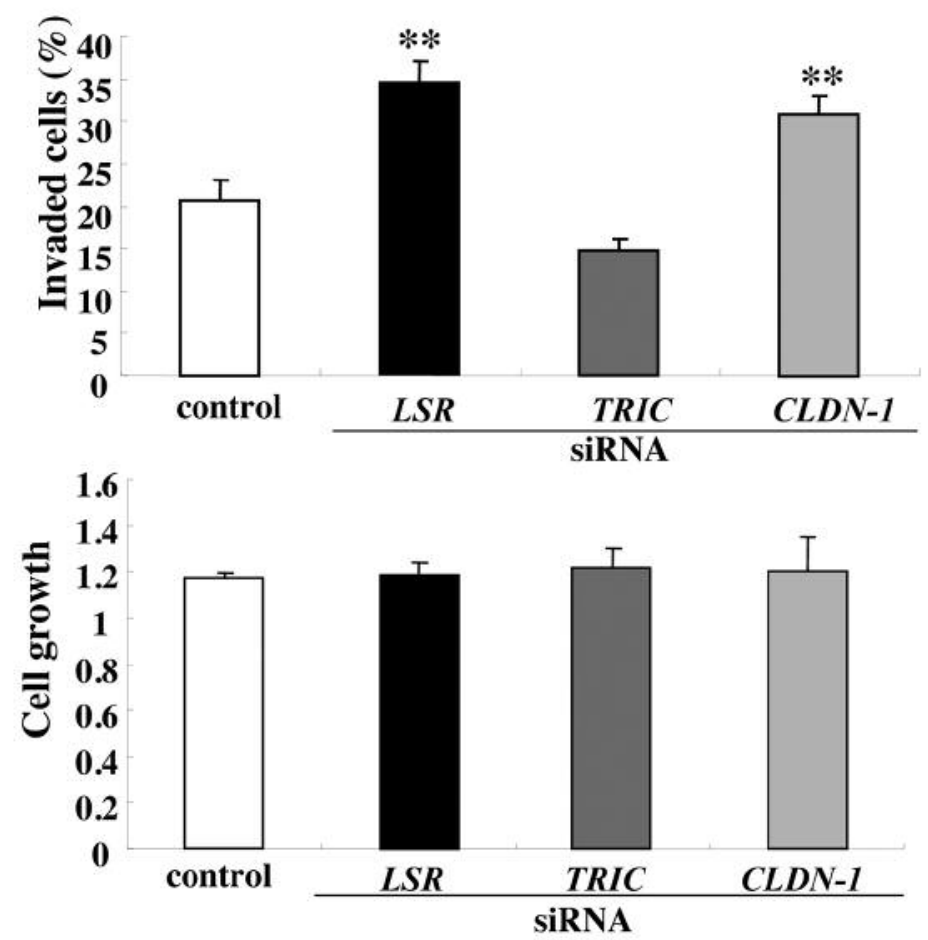

Figure 4. Knock-down of LSR by siRNA promotes cell invasiveness in Detroit562 cells. (A) RT-PCR for LSR, tricellulin (TRIC) and claudin-1 (CLDN1) in Detroit562 cells. (B) Western blot for LSR, tricellulin (TRIC) and claudin-1 (CLDN-1), (C) Matrigel invasion assay and (D) proliferation assay of Detroit562 cells treated with siRNAs of LSR, tricellulin, and claudin-1. Scale bar, $100 \mu \mathrm{m} ; * * p<0.01$. 
a

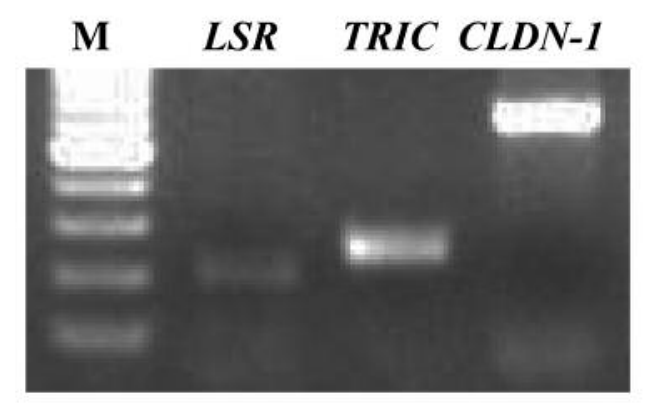

b

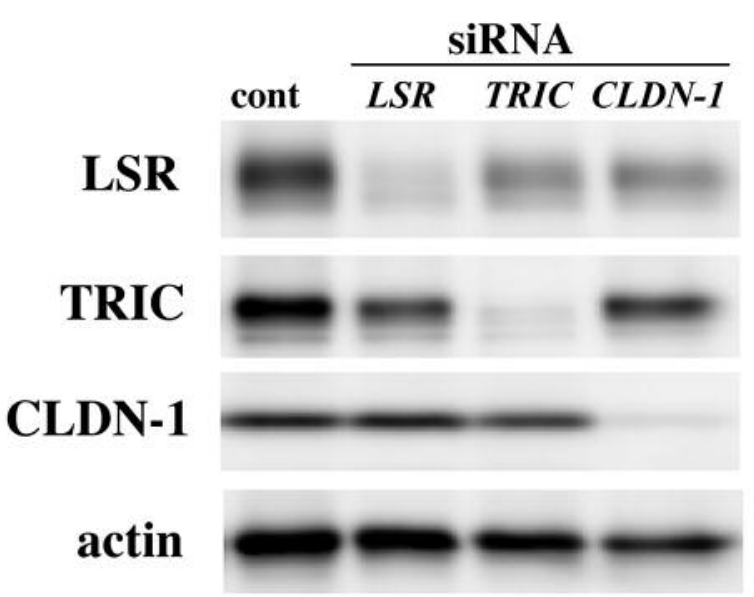

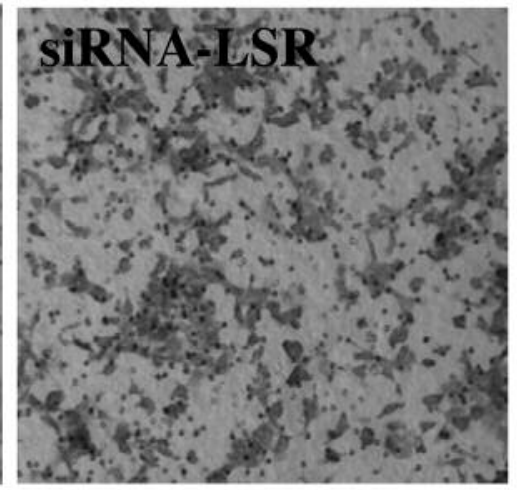
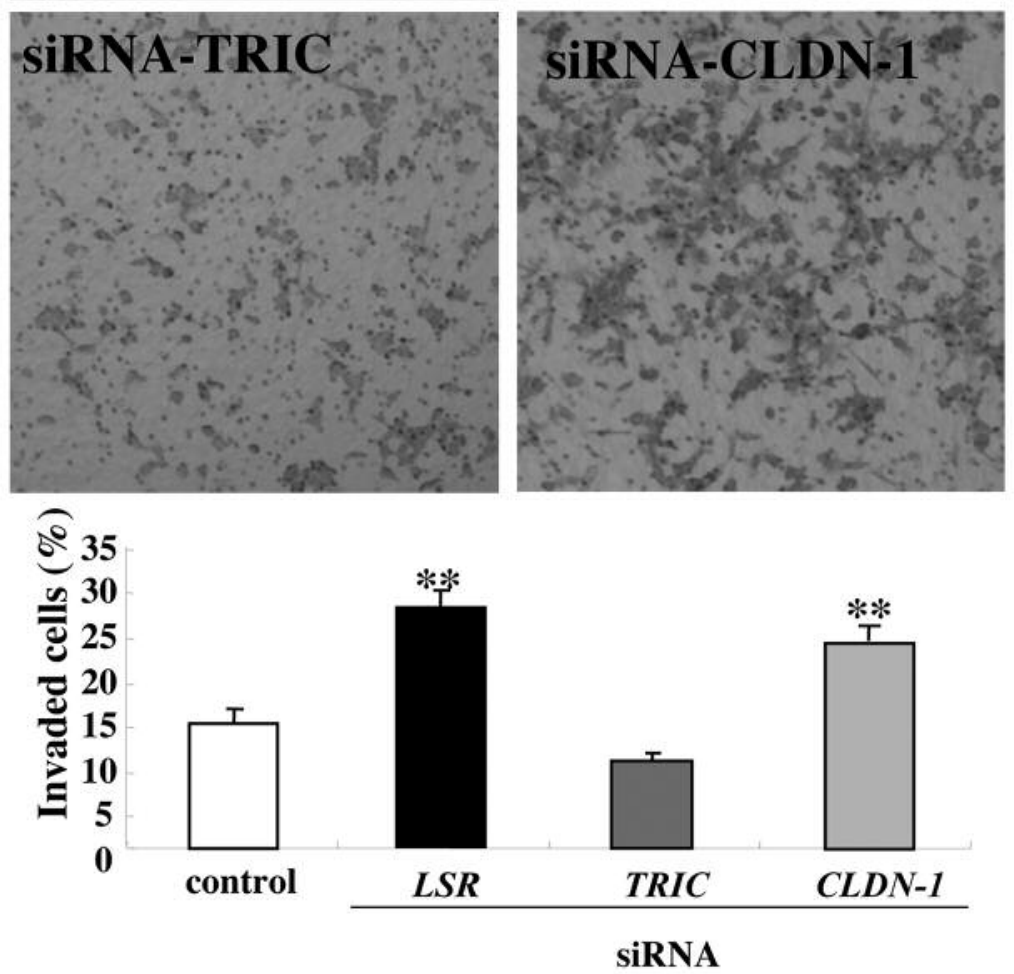

Figure 5. Knockdown of LSR by siRNA promotes cell invasiveness in primary cultured HNSCC cells. (A) RT-PCR for LSR, tricellulin (TRIC) and claudin-1 (CLDN-1) in primary cultured HNSCC cells. (B) Western blot for LSR, tricellulin (TRIC) and claudin-1 (CLDN-1), (C) Matrigel invasion assay in primary cultured HNSCC cells treated with siRNAs of LSR, tricellulin (TRIC) and claudin-1 (CLDN-1). Scale bar, $100 \mu \mathrm{m} ; * * p<0.01$. 
$\mathbf{a}$
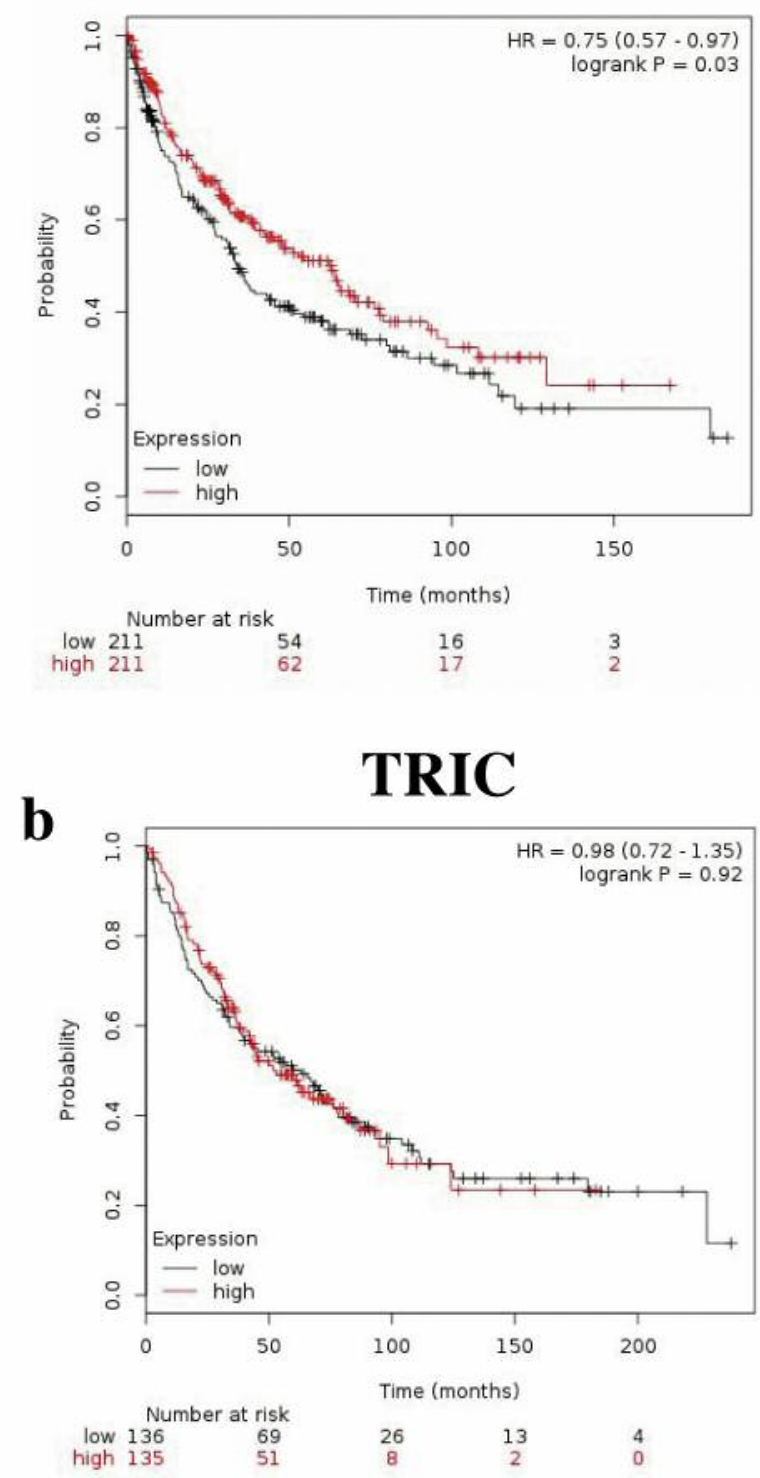

confirmed mRNA expression of LSR, TRIC and CLDN-1 (Figure 4A). LSR, tricellulin and claudin-1 diminished by the siRNAs on western blots without affecting the other two proteins (Figure 4B). Down-regulation of LSR and claudin1 but not tricellulin markedly enhanced cancer cell invasiveness (Figure 4C). However, suppression of all three proteins did not affect cell proliferation (Figure 4D).

Knockdown of LSR and claudin-1 invasiveness in primary cultured cancer cells derived from HNSCC. LSR, tricellulin and claudin-1 were knocked-down by siRNAs in primary cultured cancer cells derived from HNSCC. In primary cultured HNSCC, RT-PCR confirmed the mRNA expression

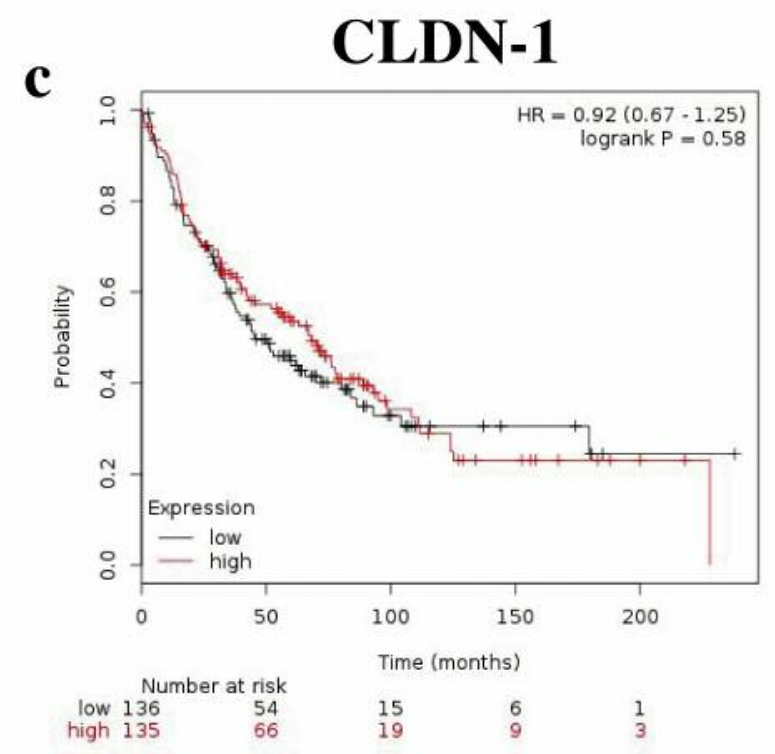

Figure 6. Kaplan-Meier survival analysis of lung cancer patients suggests that prognosis is correlated with LSR expression $(p=0.03)$ but not with tricellulin $(p=0.92)$ and claudin- $1(p=0.58)$.

of $L S R, T R I C$ and $C L D N-1$ (Figure 5A). LSR, tricellulin and claudin-1 diminished by the siRNAs on western blots without affecting the other two proteins (Figure 5B). Downregulation of LSR and claudin-1 but not tricellulin markedly enhanced cancer cell invasiveness (Figure 5C).

\section{Discussion}

Altered expression of bicellular tight junction proteins such as occludin, claudins or junctional adhesion molecule-A plays an important role in the development of head and neck and other cancers $(6,10)$. However, little is known about the tricellular junction protein LSR, especially in head and neck cancer. 
In this study, we investigated the behavior and role of LSR in head and neck squamous cell carcinoma. LSR overexpression was observed at protein and mRNA levels in cancer tissues, which also expressed MIB1, a marker of proliferation. In particular, LSR was strongly expressed in invasive tissue and $L S R$ knock-down by siRNA inhibited the invasiveness of the head and neck cancer cell line Detroit562 cells and primary cultured HNSCC cells. These results are generally consistent with our previous studies in which we have demonstrated that marked changes in LSR expression and distribution correlate with malignancy in endometriosis and endometrial cancer and, also, that down-regulation of LSR induces migration of and invasion by endometrial and bladder cancer cells $(14,15)$.

The mechanism by which loss of LSR enhances cell invasiveness in head and neck cancer is unknown. Overexpression of claudin-1 is observed in advanced-stage cancer and is associated with aggressive head and neck cancers $(6,16)$. Claudin-1 and cyclin B1 is highly expressed in hypopharyngeal squamous cell carcinoma tissues, whereas claudin-1 expression is associated with tumor differentiation degree and lymph node metastasis (17). We also reported that claudin-1 was strongly expressed, whereas claudin-7 and tricellulin were weakly expressed or were absent in HNSCC and metastatic lymph nodes (6). Conversely, a downregulation of claudin-1 has been associated with poor differentiation, portal invasion and low patient survival rates in hepatocellular carcinoma (18). In hepatocellular carcinoma and lung adenocarcinoma, enhanced invasiveness is demonstrated in association with loss of claudin-1 $(18,19)$.

In the present study, LSR was strongly expressed, as well as claudin-1, in HNSCC tissues and invasive tissues. However, knock-down of $L S R$ and claudin-1 (CLDN-1) enhanced the invasiveness of HNSCC cells in vitro. It is possible that loss of LSR may affect the malignancy of HNSCC via the same mechanisms as claudin-1.

Tight junction proteins are regulated by various cytokines and growth factors via distinct signal transduction pathways $(20,21)$. JNK and NF-kB are largely involved in the regulation of tricellular tight junctions, including tricellulin expression (22). LSR is sensitive to high-fat diets and circulating leptin, a molecule that promotes migration and invasiveness in endometriotic cells through JAK2/STAT3 signaling (23). In human endometrial cancer cell line Sawano, a decrease of LSR induced by leptin and an increase of LSR induced by adiponectin and the drugs for type 2 diabetes metformin and berberine are observed via distinct signaling pathways, including JAK2/STAT (15). In Sawano cells, metformin and berberine prevented cell migration and invasion induced by down-regulation of LSR by siRNA and leptin treatment (15). Thus, it is possible that LSR expression during head and neck tumorigenesis may in part be regulated by the adipokines leptin and adiponectin via distinct signaling pathways.
On the other hand, although we did not investigate the correlation between LSR expression and prognosis in head and neck cancer, Kaplan-Meier curves of lung squamous cell carcinoma patients (http://kmplot.com/analysis/) suggest that patients with low LSR expression had significantly poorer survival rates than patients with high LSR expression (Figure $6)$. In contrast, expression of tricellulin and claudin-1 did not show significant correlation with prognosis (Figure 6). These findings suggest that LSR expression may be significantly associated with poor disease-specific survival in various squamous cell carcinoma patients.

Our data provide new evidence that LSR inhibits the development and progression of head and neck cancer. Notably, the binary toxin Clostridium difficile transferase, for which LSR is a receptor, has been proposed as a therapeutic agent against breast cancer (13). Therefore, LSR could be a potential target in novel therapies for head and neck cancer in the same manner as claudin-4, which is now targeted in approaches based on Clostridium perfringens enterotoxin.

\section{Conflicts of Interest}

The Authors declare no conflict of interest.

\section{Acknowledgements}

This work was partially supported by a Grant-in-Aid for Scientific Research from the Ministry of Education, Culture, Sports, Science, and Technology, Japan (Grant no. 25861575).

\section{References}

1 Matta A and Ralhan R: Overview of current and future biologically based targeted therapies in head and neck squamous cell carcinoma. Head Neck Oncol 1: 6, 2009.

2 Furuse $\mathrm{M}$ and Tsukita $\mathrm{S}$ : Claudins in occluding junctions of humans and flies. Trends Cell Biol 16: 181-188, 2006.

3 Ikenouchi J, Furuse M, Furuse K, Sasaki H, Tsukita S and Tsukita S: Tricellulin constitutes a novel barrier at tricellular contacts of epithelial cells. J Cell Biol 171: 939-945, 2005.

4 Masuda S, Oda Y, Sasaki H, Ikenouchi J, Higashi T, Akashi M, Nishi E and Furuse M: LSR defines cell corners for tricellular tight junction formation in epithelial cells. J Cell Sci 124: 548$555,2011$.

5 Martin TA: The role of tight junctions in cancer metastasis. Semin Cell Dev Biol 36: 224-231, 2014.

6 Kondoh A, Takano K, Kojima T, Ohkuni T, Kamekura R, Ogasawara N, Go M, Sawada N and Himi T: Altered expression of claudin-1, claudin-7, and tricellulin regardless of human papilloma virus infection in human tonsillar squamous cell carcinoma. Acta Otolaryngol 131: 861-868, 2011.

7 Patonai A, Erdélyi-Belle B, Korompay A, Somorácz A, Straub BK, Schirmacher P, Kovalszky I, Lotz G, Kiss A and Schaff Z: Claudins and tricellulin in fibrolamellar hepatocellular carcinoma. Virchows Arch 458: 679-688, 2011. 
8 Korompay A, Borka K, Lotz G, Somorácz A, Törzsök P, ErdélyiBelle B, Kenessey I, Baranyai Z, Zsoldos F, Kupcsulik P, Bodoky $\mathrm{G}$, Schaff $\mathrm{Z}$ amd Kiss A: Tricellulin expression in normal and neoplastic human pancreas. Histopathology 60: E76-86, 2012.

9 Masuda R, Semba S, Mizuuchi E, Yanagihara K and Yokozaki $\mathrm{H}$ : Negative regulation of the tight junction protein tricellulin by snail-induced epithelial-mesenchymal transition in gastric carcinoma cells. Pathobiology 77: 106-113, 2010.

10 Kakuki T, Kurose M, Takano KI, Kondoh A, Obata K, Nomura K, Miyata R, Kaneko Y, Konno T, Takahashi S, Hatakeyama T, Kohno T, Himi T and Kojima T: Dysregulation of junctional adhesion molecule-A via p63/GATA-3 in head and neck squamous cell carcinoma. Oncotarget (in press).

11 Somorácz A, Korompay A, Törzsök P, Patonai A, Erdélyi-Belle B, Lotz G, Schaff Z and Kiss A: Tricellulin expression and its prognostic significance in primary liver carcinomas. Pathol Oncol Res 20: 755-764, 2014.

12 Schlachter K, Gyugos M, Halász J, Lendvai G, Baghy K, Garami M, Gyöngyösi B, Schaff Z and Kiss A: High tricellulin expression is associated with better survival in human hepatoblastoma. Histopathology 65: 631-641, 2014.

13 Reaves DK, Fagan-Solis KD, Dunphy K, Oliver SD, Scott DW and Fleming JM: The role of lipolysis stimulated lipoprotein receptor in breast cancer and directing breast cancer cell behavior. PLoS One 9: e91747, 2014.

14 Herbsleb M, Birkenkamp-Demtroder K, Thykjaer T, Wiuf C, Hein AM, Orntoft TF and Dyrskjøt L: Increased cell motility and invasion upon knockdown of lipolysis stimulated lipoprotein receptor (LSR) in SW780 bladder cancer cells. BMC Med Genomics 1: 31, 2008.

15 Shimada H, Satohisa S, Kohno T, Takahashi S, Hatakeyama T, Konno T, Tsujiwaki M, Saito T and Kojima T: The roles of tricellular tight junction protein lipolysis-stimulated lipoprotein receptor in malignancy of human endometrial cancer cells. Oncotarget (in press).

16 Sappayatosok K and Phattarataratip E: Overexpression of claudin- 1 is associated with advanced clinical stage and invasive pathologic characteristics of oral squamous cell carcinoma. Head Neck Pathol 9: 173-180, 2015.
17 Li W, Dong Q, Li L, Zhang Z, Cai X and Pan X: Prognostic significance of claudin-1 and cyclin B1 protein expression in patients with hypopharyngealsquamous cell carcinoma. Oncol Lett 11: 2995-3002, 2016.

18 Higashi Y, Suzuki S, Sakaguchi T, Nakamura T, Baba S, Reinecker HC, Nakamura S and Konno H: Loss of claudin-1 expression correlates with malignancy of hepatocellular carcinoma. J Surg Res 139: 68-76, 2007.

19 Chao YC, Pan SH, Yang SC, Yu SL, Che TF, Lin CW, Tsai MS, Chang GC, Wu CH, Wu YY, Lee YC, Hong TM and Yang PC: Claudin-1 is a metastasis suppressor and correlates with clinical outcome in lung adenocarcinoma. Am J Respir Crit Care Med 179: 123-133, 2009.

20 González-Mariscal L, Tapia R and Chamorro D: Crosstalk of tight junction components with signaling pathways. Biochim Biophys Acta 1778: 729-756, 2008.

21 Takano K, Kojima T, Sawada N and Himi T: Role of tight junctions in signal transduction: an update. EXCLI J 13: 114562, 2014.

22 Kojima T, Fuchimoto J, Yamaguchi H, Ito T, Takasawa A, Ninomiya T, Kikuchi S, Ogasawara N, Ohkuni T, Masaki T, Hirata K, Himi T and Sawada N: c-Jun N-terminal kinase is largely involved in the regulation of tricellular tight junctions via tricellulin in human pancreatic duct epithelial cells. J Cell Physiol 225: 720-733, 2010.

23 Stenger C, Hanse M, Pratte D, Mbala ML, Akbar S, Koziel V, Escanyé MC, Kriem B, Malaplate-Armand C, Olivier JL, Oster $\mathrm{T}$, Pillot $\mathrm{T}$ and Yen FT: Up-regulation of hepatic lipolysis stimulated lipoprotein receptor by leptin: a potential lever for controlling lipid clearance during the postprandial phase. FASEB J 24: 4218-28, 2010 